\title{
What Went Wrong? Feeling Like a Fraud
}

\author{
Inanda Shinta Anugrahani
}

${ }^{I}$ State University of Malang
${ }^{*}$ Corresponding author. Email: inanda.shinta.fe@um.ac.id.

\begin{abstract}
This study discusses dysfunctional behaviour that occurs from the students and employees' point of view who have work experience in an unhealthy environment. The results of a survey from 20 respondents as sources in this study can be concluded that fraud occurs in everyday life becomes a justification if it is committed by many people. Dishonesty becomes a habit for individuals to repeat it. Someone will make up a new lie to cover up another lie. If humans are allowed to have a culture of dishonesty, then fraud will only become a feeling. Everything that should be considered illegal, it being a legal in implementation.
\end{abstract}

Keywords: fraud, dysfunctional behaviour, personality

\section{INTRODUCTION}

Cheating is dysfunctional behaviour committed by someone in a conscious state. Some of conditions causing someone to commit fraud are pressure, opportunity, and rationalization. Pressure is a persons' motivation to commit fraud because of demands, incentives, and the needs. Pressure causes an individual to have the courage to do anything to achieve goals. The feeling of pressure experienced by people causes fraudulent behaviour becomes a new habit to cover up previous crimes. In a job, employees are frequently faced with two choices, obeying what was ordered by their leader or ignore it. Not all leaders in the occupation are honest in doing something, sometimes the pressure comes when leaders have the ambition to achieve a desired goal illegally.

In Indonesia, several institutions still use this expression as a culture "The winner is boss' favourite". This puts pressure on employees that they have desire to sell their

\section{LITERATURE REVIEW}

Locke (1968) explained that individuals' behaviour determined by two cognitions, namely (1) values, defined as things appreciated by individuals as an effort to gain prosperity and (2) intentions (goals). If an integrity to get an expected position. Several conditions also show that smart and idealistic employees being ignored sometimes. In a healthy work environment, leaders have a very important role on employees' performance. A good work environment will increase employee organizational commitment which indirectly increase employees' performance. It means that a healthy work environment will affect employees job satisfaction thereby minimizing a fraud.

The cases of fraud committed by employees and superiors at work today cannot be separated from the phenomena of academic fraud committed by many students. Academic fraud committed by students can take various forms, including cheating during exams and copying colleagues' work. This dishonesty has major implications for future behaviour. Therefore, special research is needed to investigate the causes of fraudulent behaviours which have begun to be considered commonplace.

individual has set goals for behaviour in the future, these goals will affect the actual behaviour that will occur in individuals' future. Fritz (1958) argued that an individuals' behaviour determined by a combination of internal and external intensity. Therefore, 
individuals will be motivated to understand their environment and the causes of certain events. The domination of internal and external factors existing in individuals will be a determining factor for a persons' behaviour.

Leaders with a high commitment to their organization tend not to cheat in achieving the goals, because they feel that the responsibility they assume is not only the result, but also the process in achieving the result must be in accordance with the procedures. The existence of external pressure can also be managed properly so that fraudulent behaviour can be minimized. Religious factors inherent in each individual also influence their decisions in choosing honest or cheat.

The dissent between leaders and employees causes a feeling of discomfort at work. This will reduce employees' performance. Some of them will choose to stay and follow leaders' direction even though it is not according to their conscience. The others chose to resign in order to maintain work integrity and professionalism. Integrity is a quality that underlies public trust and it is a benchmark for members to test all their decisions. Integrity requires an individual to be honest and transparent, brave, wise and responsible in carrying out their job. A persons' professionalism will appear when they are capable to maintain their integrity by obeying the prevailing rules and norms.

Opportunity is a situation that opens up the probability of fraud. The opportunity of fraud occurred due to the weakness of internal controls, lack of supervision, and authority abuse. The opportunity for an individual to commit a fraud can be minimized by implementing control procedures and early detection of fraud. The existence of weak control will provide a great opportunity for the perpetrator to cheat (Donelson, Ege, \& Mcinnis, 2017). Opportunities to do a fraud committed by employees sometimes arise due to support from their seniors. To achieve the goals desired by seniors, they will allow their subordinates to cheat.

Rationalization is the attitude or character used by fraudsters to seek justification for fraudulent acts. The aspect of justification committed by the perpetrator of a fraud is based on the feeling that the action taken is something other people have usually done, so that something that is wrong becomes right. Some of the causes of cheating that are ignored as a natural occurrence happened because individuals think that the achievement of goals is more important than the process.

Wolfe \& Hermason (2004) explained that pressure is an act of cheating that occurs due to the desires and needs of individuals. Pressure can cause people have the courage to behave defiantly to fulfil their wishes. people can act fraudulently when they gets the opportunity to exploit a weakness in the system. Opportunities can arise either in a planned manner or spontaneously. A disharmonious environment and ineffective regulation can support people intention to cheat. The act of cheating can occur on selfjustification that the action taken is proportional to the risks (Wolfe \& Hermason, 2004). The thought and justification that unethical actions carried out by the perpetrator of fraud are normal if it is committed by several people.

Perls (1973) stated that individuals with good personality have full awareness and acceptance of themselves. Individuals with good personalities can accept and understand their strengths and aware of their potential. Personality can be formed from the nature of the individual since they born and the environment in which the individuals live. Personality can be formed from childhood in the family environment. However, as an adult, the school and work environment will affect individuals' personality. When there are many actions that are not according to the rules, but are often carried out by people in general, this will be considered as normal.

Organizational culture has an important role in minimizing the occurrence of cheating in work environment. Organizational culture has a very strategic role to encourage and improve the effectiveness of organizational performance, especially employee performance both in the short and long term. The role of organizational culture is as a medium to determine the direction of the organization, directing what can and should not be done, how to allocate organizational resources and also as a medium to deal with problems and opportunities from the organizational environment. The practice of fraud is still very difficult to detect by the public due to the lack of government regulations governing whistle-blower systems (Christian, 2020). This will be an opportunity for the perpetrators to commit fraud because they feel that they are in safe position. 
Desai, Jain, Jain, \& Tripathy (2020) explained the difference in evaluating the morality of an action, entity theory focuses on punishing behaviour based on negative traits. In contrast, improvement theory focuses more on corrective actions based on mediating factors or circumstances. The form of

\section{RESEARCH METHOD}

The method used in this research is online discussion in the group in which being studied. Participants will be given several questions that must be answered and will be responded by other participants. This research was also conducted in a survey via google form to determine ten participants from the group of employees and ten participants from accounting students. In this study, participants were given an opportunity to explain their opinions. There is no coercion from researchers to reveal things that are confidential and do not want to be conveyed during online discussions.

\section{RESULTS AND DISCUSSION}

The survey was conducted on 10 employees and 10 students regarding expectations of cheating occurred at work. There are seven (7) from 10 students stated that they had cheated on an exam. They argued that cheating behaviour is common form among academics. They argued that as long as it does not bring disadvantage to others, it is not a crime. Students who agreed with cheating on the exam explained that under conditions of pressure and opportunity, this is justified because it will affect their career in finding work in the future. It is contrast with three students, who considered that cheating was immoral and self-defeating. They argued that God is always watching whatever people do. They think that cheating will become the root for them to get used to corruption while working.

Students consider that delaying assignments is a factor that makes them prefer cheating to trying to do the task by themselves. They feel hesitant to answer because they do not understand the material being tested. The habit of procrastinating becomes a culture for students because of the assumption that there is no specific standard of assessment by the teacher. Students think that studying on a short time will provide maximum results compared to studying in advance. negotiation is not always effective in solving the problem of fraud. Based on facts related to various individual personalities. The appropriate form of punishment for each of the perpetrators of fraud will also vary.

From the employees point of view, cheating can occur anywhere as long as there is an intention and opportunity. From ten employees, there are nine employees stated that they knew their boss had cheated in achieving the goals. They argued that the fraud committed by their superiors is a justified error in order to increase the chances of achieving organizational goals. Those nine employees expressed their choice to remain silent because they still need the job. One employee think that they do not care about what is done by their leader.

Employees who have work experience in various places will compare current forms of leadership with previous ones. They compare how the leader solve the problems to achieve the desired goals. The habit of cheating will give a view that cheating is a common thing to do in a work environment. The power offered through a position supports someone to cheat. Success gives strength to the individual as well as exerts pressure. When success is measured by the achievement, people will do anything to achieve them, even though use a bad way, violating the norms.

The authority provides a gap to leaders to engage the dysfunctional behaviour in achieving goals. Dysfunctional behaviour becomes disguised when it is committed by many people. When an action provides benefits to the organization, then this action is considered normal. Respondents agree that weak policies and procedures regarding human resources become a potential source for employees to commit a fraud. Respondents argued that the solution to reduce a fraud is implementing the planning, organizing, actuating, controlling, and evaluating. The effectiveness of implementing rules and work culture that is able to synergize with every aspect of the organization will minimize a persons' intention to commit fraud, not only focusing on improving an internal control system, but also implementing clear penalties will be a solution to minimize fraud. 


\section{CONCLUSIONS}

There are many factors a person commits fraud. The intention to commit fraud is not only based on one's own desire, but on external influences. Fraud that occurs repeatedly and becomes a

\section{REFERENCES}

[1]. Christian, N. (2020) Behavioural strategy analysis using the fraud diamond theory approach to detecting corporate fraud in Indonesia. International Journal of Business and Management Invention (IJBMI), 9(4), 66-74.

[2]. Desai, N., Jain, S. P., Jain, S., \& Tripathy, A. (2020). The impact of implicit theories of personality malleability on opportunistic financial reporting. Journal of Business Research, 116(c), 258-265. Doi: 10.1016/j.jbusres.2020.05.043.

[3]. Donelson, D., Ege, M., \& Mcinnis, J. M. (2017). Internal control weaknesses and financial habit will become justification. The solution to minimize fraud is to increase effectiveness in the implementation of planning, organizing, actuating, controlling, and evaluating.

reporting fraud. Auditing: A Journal of Practice Theory, 36(3), 45-69.

[4]. Fritz, H. (1958). The psychology of interpersonal relations. New York: Wiley.

[5]. Locke, E. A. (1968). Toward a theory of task motivation and incentives. Organizational behaviour and human performance, 3(2), 157189.

[6]. Perls, F. (1973). The Gestalt approach \& eye witness to therapy. California: Science \& Behaviour Books.

[7]. Wolfe, D. T., \& Hermanson, D. R. (2004). The fraud diamond: Considering the four elements of fraud. CPA Journal, 74(12), 38-42. 